\title{
STRUCTURE AND VIBRATIONAL ASSIGNMENTS FOR $\mathrm{PCl}_{5}$. AN ELECTRON DIFFRACTION STUDY*
}

\author{
W. J. ADAMS AND L. S. BARTELL** \\ University of Michigan, Ann Arbor, Mich. 48104 (U.S.A.)
}

(Received May 18th, 1970)

\section{ABSTRACT}

Gas-phase phosphorus pentachloride is a trigonal bipyramid with axial bonds $0.10_{4} \pm 0.01 \AA$ (e.s.d.) longer than equatorial bonds. The mean bond lengths are $2.061 \pm 0.002 \AA$. Amplitudes of vibration were determined, resolving the ambiguity in the $e_{1}{ }^{\prime}$ bending assignments in favor of $v$ (axial bend) $>v$ (equatorial in-plane bend). Structural and vibrational features were in accord with GillespieNyholm theory.

\section{INTRODUCTION}

The Group Va pentahalides studied to date in the gas phase are trigonal bipyramids with axial bonds longer than equatorial bonds ${ }^{1-6}$. Many theoretical models account qualitatively for these structural characteristics. One of the simplest of the models, the valence-shell-electron-pair-repulsion (VSEPR) model of Gillespie and $\mathrm{Nyholm}{ }^{7,8}$ also predicts that the difference between the axial and equatorial bonds should increase as the ligand electronegativity decreases. A comparison of $\mathrm{PF}_{5}{ }^{1}$ and $\mathrm{PCl}_{5}{ }^{3-5}$ seems to bear this out, but there are appreciable differences between the bond lengths reported for the latter molecule. A redetermination of the structure of gaseous $\mathbf{P C l}_{5}$ by electron diffraction would help to resolve this problem and would, in addition, shed useful new light on the molecular force field. By establishing the mean amplitudes of vibration, which have not been reported heretofore, electron diffraction should settle the longstanding ambiguity in the assignments for the $e^{\prime}$ frequencies.

\footnotetext{
- This research was supported by a grant from the National Science Foundation.

** Author to whom correspondence concerning reprints should be addressed.
} 


\section{EXPERIMENTAL PROCEDURE}

Reagent grade phosphorus pentachloride was purchased from the J. T. Baker Chemical Co., Phillipsburg, N.J. Care was taken to prevent decomposition of the sample by transferring it from the shipping container to a suitable sample flask in a dry nitrogen atmosphere. The sample was sublimed to the walls of the sample flask, and volatile impurities were removed by pumping prior to recording each set of diffraction patterns.

An early vapor pressure study of phosphorus pentachloride ${ }^{9}$ indicated that slight association occurs at temperatures below $100^{\circ} \mathrm{C}$ while at temperatures above $110^{\circ} \mathrm{C}$ dissociation to phosphorus trichloride and chlorine becomes important. A recent mass spectral study ${ }^{10}$ has given supporting evidence for association $\left(\mathrm{P}_{2} \mathrm{Cl}_{10}{ }^{+}\right.$observed) at room temperature. To reduce these complicating effects and to keep exposure times from being excessively long, the sample was introduced into the diffraction chamber through a monel and nickel nozzle assembly heated to $100^{\circ} \mathrm{C}$. Diffraction patterns were recorded on $4 \times 5$ in. Kodak process plates at several camera distances using an electron diffraction apparatus ${ }^{11,12}$ equipped with an $r^{3}$ sector. The experimental conditions under which the diffraction patterns were recorded using $40 \mathrm{kV}$ electrons are given in Table 1 . Plates were developed at $20^{\circ} \mathrm{C}$ for 5 min with Kodak D-11 developer.

TABLE 1

CONDITIONS UNDER WHICH $\mathrm{PCl}_{5}$ DIFFRACTION PATIERNS WERE RECORDED

\begin{tabular}{lccc}
\hline Camera distance $(\mathrm{cm})$ & 21.290 & 10.641 & 6.776 \\
Sample temperature $\left({ }^{\circ} \mathrm{C}\right)$ & 80 & 90 & 90 \\
Vapor pressure (torr) & 7.8 & 16 & 16 \\
Exposure time $(\mathrm{sec})$ & $7-8$ & $30-35$ & 75 \\
Beam current $(\mu \mathrm{A})$ & 0.42 & 0.46 & 0.42
\end{tabular}

Nozzle throat $0.029 \mathrm{~cm}$ in diameter by $0.070 \mathrm{~cm}$ long.

Photographic densities, measured with an automatic recording microphotometer with digital output ${ }^{13}$, were converted to absorbances. Six plates at each camera distance were averaged and used in the structural analysis.

\section{ANALYSIS OF DATA}

Experimental leveled intensity, $I_{0}(s)$, and background intensity, $I_{\mathrm{B}}(s)$, functions ${ }^{14}$, computed for each of the three camera distances with the use of analytical scattering factors ${ }^{15,16}$, are available from ASIS*. Indices of resolution ${ }^{17}$ were 1.07, 1.06 and 1.03 for the 21-, $11-$, and 6.5-cm camera distances, respectively.

* For a listing of experimental intensity data, order Document No. 01092 fromAsIS National Auxiliary Publications Service, c/o CCM Information Sciences; Inc., 22 West 34th Street, New York, N.Y., 10001, U.S.A.; remitting $\$ 1.00$ for microfiche or $\$ 3.00$ for photocopies. 
Experimental and calculated molecular intensities and radial distribution functions were computed as previously described ${ }^{14,17,18}$ with the usual corrections applied $^{17,19-21}$. Radial distribution functions were calculated using a Degard damping factor $\left[\exp \left(-0.0015 a^{2}\right)\right]$. Atomic scattering factors used in all phases of the analysis after leveling of experimental intensities were the partial wave elastic factors of Cox and Bonham ${ }^{22}$ and the inelastic factors of Tavard et al. ${ }^{23}$. Anharmonicity constants ${ }^{20}$ were estimated ${ }^{24}$ to be $1.6 \AA^{-1}$ for the $\mathrm{P}-\mathrm{Cl}$ bonded distance and were taken to be $1.0 \AA^{-1}$ for the $\mathrm{Cl} \cdots \mathrm{Cl}$ nonbonded distances.

Soon after the structural analysis began it became apparent that an impurity had been present in the sample. A broad impurity peak in the radial distribution function at 1.4 $\AA$, together with infrared spectral analysis of the vapors issuing from the nozzle of the diffraction apparatus showed these impurities to be phosphoryl chloride and hydrogen chloride. The $\mathrm{P}-\mathrm{O}$ and $\mathrm{H}-\mathrm{Cl}$ distances account for the appearance of a peak in the radial distribution function at $1.4 \AA$. These impurities were apparently formed during the diffraction experiments by hydrolysis of $\mathbf{P C l}_{5}$, perhaps by water from photographic plates. Estimates of the $\mathbf{P O C l}_{3}$ present at each camera distance were 15,8 , and 8 mole $\%$ at the $21-, 11-$, and $6.5-\mathrm{cm}$ camera distances as inferred from the diffraction. The mole ratio of $\mathrm{FOCl}_{3}$ to $\mathrm{HCl}$ was taken as 1 to 2 .

Corrections for the impurities were made by subtracting the intensity contribution due to these impurities from the experimental leveled intensities using appropriate theoretical expressions and the known molecular structures of $\mathrm{POCl}_{3}{ }^{25,26}$ and $\mathrm{HCl}^{27}$.

The radial distribution function, the molecular intensity of each camera distance, and the composite molecular intensity were fitted by the appropriate calculated expressions in least squares analyses ${ }^{28}$ of both the corrected and uncorrected data. Small corrections were made for Bastiansen-Morino shrinkage effects $^{29}$ in geometrically constrained least squares analyses. These shrinkage corrections, taken from the calculations of Brunvoll $^{30}$, were $0.0007 \AA$ for $\mathrm{Cl}_{\mathrm{ax}} \cdots \mathrm{Cl}_{\mathrm{eq}}, 0.007 \AA$ for $\mathrm{Cl}_{\mathrm{eq}} \cdots \mathrm{Cl}_{\mathrm{eq}}$, and $0.0025 \AA$ for $\mathrm{Cl}_{\mathrm{ax}} \cdots \mathrm{Cl}_{\mathrm{ax}}$.

The difference between the mean amplitudes of vibration for the axial and equatorial $\mathrm{P}-\mathrm{Cl}$ bond lengths, $\Delta l$, was taken from Brunvoll $^{30}$ and included as a constraint in the analysis since it was not possible to establish independent values of $l_{\mathrm{ax}}$ and $l_{e q}$ from the diffraction intensities. The value of $\Delta l$ calculated by Brunvoll is approximately twice the value estimated with the aid of an approximation ${ }^{31}$ based on Badger's rule ${ }^{32}$ which relates variations in force constants to variations in bond lengths.

RESULTS

Experimental and calculated molecular intensities, $s M(s)$, are compared in 
Fig. 1. The experimental radial distribution function is shown in Fig. 2 and is compared with the calculated distribution function. The positions and areas of the four well-resolved peaks in the experimental radial distribution function are in agreement with a trigonal bipyramidal structure except for small discrepancies in the

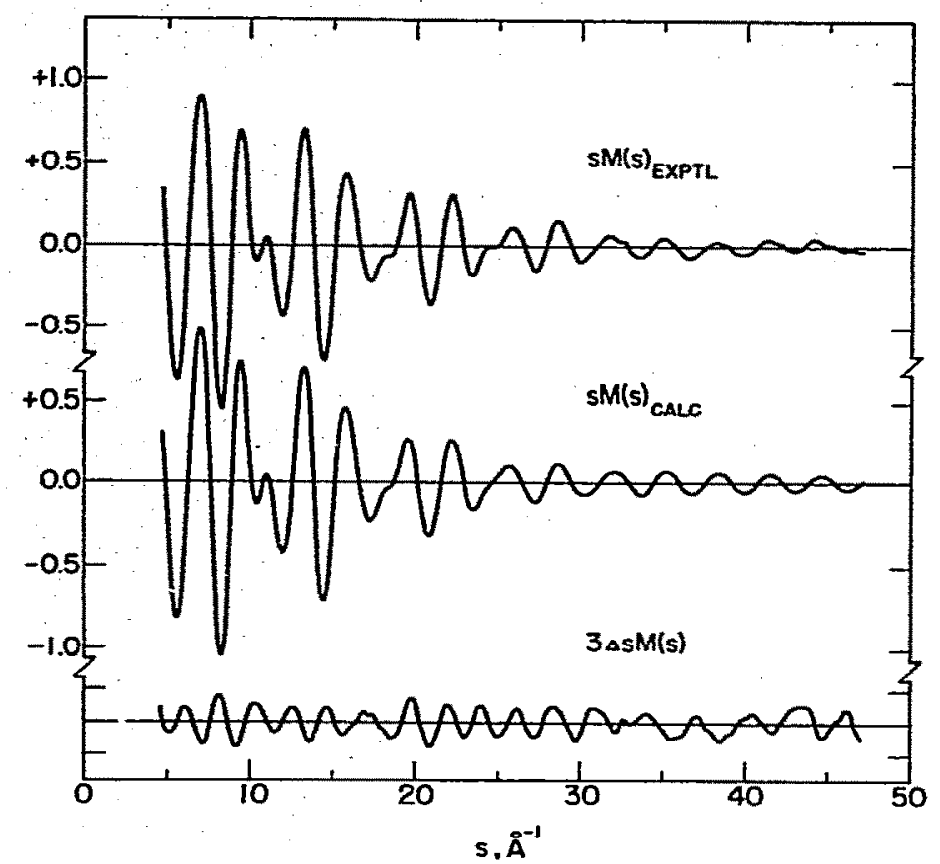

Fig. 1. Experimental and calculated molecular intensity curves for $\mathrm{PCl}_{s} . \Delta s M(s)=\left[s M(s)_{\text {expn }}-\right.$ $\left.s M(s)_{\text {cale }}\right]$.

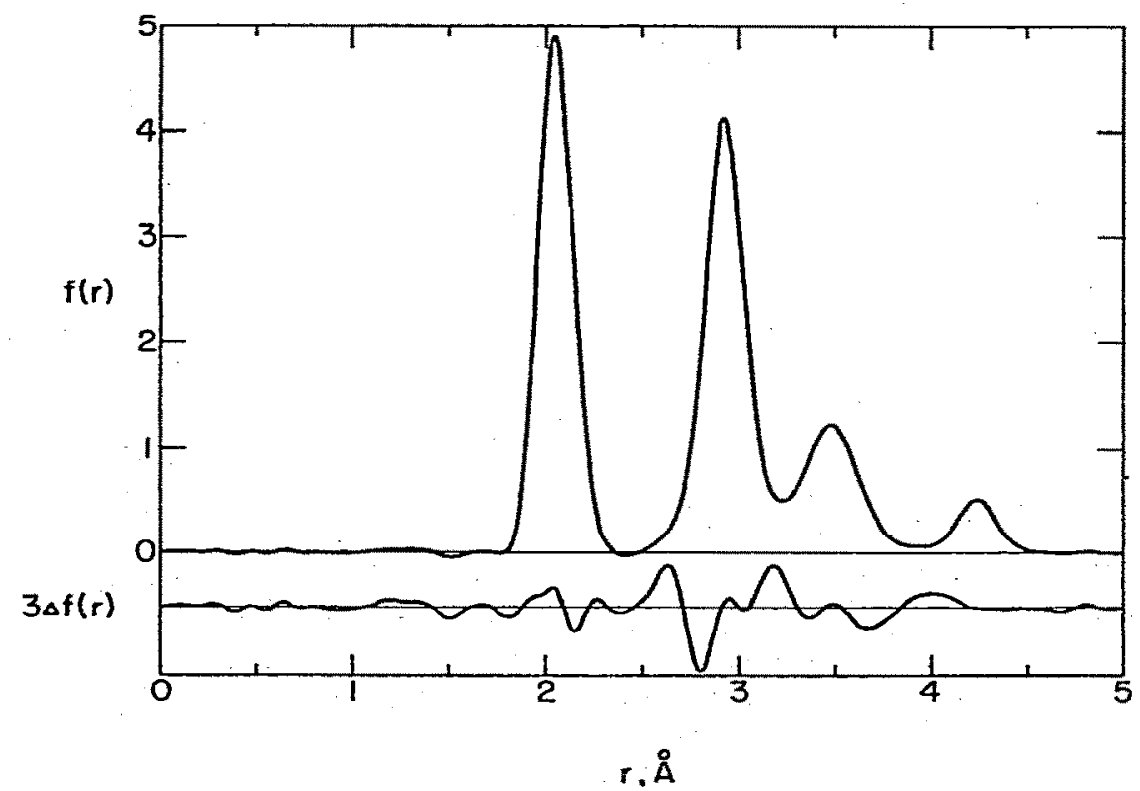

Fig. 2. Experimental radial distribution curve for $\mathrm{PCl}_{s} . \Delta f(r)=\left[f(r)_{\text {expu }}-f(r)\right.$ esie $]$. 
$2.9 \AA$ region. This discrepancy arises from scattered intensities at small scattering angles. Intensities from scattering angles beyond $s=12 \AA^{-1}$ contribute virtually nothing to the anomalous area.

The effect of vapor composition on least squares analyses of the molecular. intensity for each camera distance was analyzed in detail. It was found that the mean bond length, $(\mathrm{P}-\mathrm{Cl})_{\text {mean }}$, is relatively insensitive to the $\mathrm{POCl}_{3}$ and $\mathrm{HCl}$ impurities present in the vapor, while the difference between axial and equatorial bond lengths, $\Delta(\mathbf{P}-\mathrm{Cl})$, is moderately sensitive.

Structural parameters and estimated standard errors derived from least squares analyses are given in Table 2 . The mean amplitudes of vibration are compared with those calculated by Brunvoll $^{30}$ for a temperature of $298{ }^{\circ} \mathrm{K}$. Estimated

TABLE 2

STRUCTURAL PARAMETERS (IN Å) AND ESTIMATED STANDARD ERRORS² FOR PCl

\begin{tabular}{|c|c|c|c|c|}
\hline Parameter & $r_{a}$ & $l_{q}$, exptl. & $I_{\sigma}$, calcd. ${ }^{\mathrm{b}} 298^{\circ} \mathrm{K}$ & $383^{\circ} K^{c}$ \\
\hline$(\mathrm{P}-\mathrm{Cl})_{\text {mean }}$ & $2.061 \pm 0.002$ & & & \\
\hline$\left(\mathrm{P}-\mathrm{Cl} \mathrm{l}_{a x}\right)-\left(\mathrm{P}-\mathrm{Cl}_{\mathrm{eq}}\right)$ & $0.104 \pm 0.01$ & & & \\
\hline$\left(\mathrm{P}-\mathrm{Cl}_{\mathrm{eq}}\right)$ & $2.020 \pm 0.007$ & $0.047 \pm 0.005$ & $0.050(0.052)$ & $0.053(0.056)$ \\
\hline$\left(\mathrm{P}-\mathrm{Cl}_{\mathbf{2 x}}\right)^{\mathrm{d}}$ & $2.124 \pm 0.009$ & $0.055 \pm 0.005$ & $0.058(0.058)$ & $0.062(0.062)$ \\
\hline $\mathrm{Cl}_{\mathrm{ax}} \cdots \mathrm{Cl}_{\mathrm{eq}}$ & $2.930 \pm 0.012$ & $0.091 \pm 0.004$ & $0.073(0.102)$ & $0.080(0.116)$ \\
\hline $\mathrm{Cl}_{\mathrm{eq}} \cdots \mathrm{Cl}_{\mathrm{eq}}$ & $3.491 \pm 0.010$ & $0.146 \pm 0.007$ & $0.126(0.068)$ & $0.142(0.075)$ \\
\hline $\mathrm{Cl}_{2 x} \cdots \mathrm{Cl}_{2 x}$ & $4.245 \pm 0.010$ & $0.081 \pm 0.006$ & $0.060(0.060)$ & $0.066(0.066)$ \\
\hline
\end{tabular}

2 The effects of both random and systematic errors were taken into account in computing standard errors, (ref. 12, neglecting interactions implicit in eqn. (27) of this reference). The effects of uncertainties in the concentration were also included.

- See ref. 30. Values in parentheses are consistent with a vibrational assignment of the equatorial bending frequency greater than the axial bending frequency; the other values are based on the opposite assumption.

c Computed assuming mean square amplitudes vary as coth $\left(h v_{\text {err }} / 2 k T\right)$; see text.

d $l_{\mathrm{g}}\left(\mathrm{P}-\mathrm{Cl} \mathrm{I}_{\mathrm{nz}}\right)-l_{\mathrm{g}}\left(\mathrm{P}-\mathrm{Cl} \mathrm{l}_{\mathrm{eq}}\right)$ was constrained to be $0.008 \AA$ in the analysis as taken from ref. 30.

amplitudes at $383^{\circ} \mathrm{K}$ are also listed. They were calculated roughly from Brunvoll's $298^{\circ} \mathrm{K}$ values by assuming that mean square amplitudes vary as coth $\left(h v_{\text {eff }} / 2 k T\right)$, where $v_{\text {eff }}$ is a weighted average frequency of the modes contributing most heavily to the particular amplitude. The temperature $383^{\circ} \mathrm{K}$ was adopted arbitrarily, assuming the temperature drop of the sample upon free expansion was $15^{\circ}$. The actual drop appropriate for vibrational relaxation is unknown and may be very different from this figure. Results of the present study are compared with those of previous electron diffraction studies in Table 3.

A matrix of correlation coefficients, based on a least squares fit of the composite molecular intensity using a diagonal weight matrix with elements proportional to the scattering variable $s$, is given in Table 4. 
TABLE 3

COMPARISON OF ELECTRON DIFFRACTION STUDIES OF PCl $\mathrm{PC}_{5}$

\begin{tabular}{|c|c|c|c|c|}
\hline & \multicolumn{4}{|l|}{ Parameter $(A)$} \\
\hline & $(P-C l)_{\text {mean }}$ & $\Delta(P-C l)^{\mathrm{a}}$ & $P-C l_{\text {eq }}$ & $P-C I_{a x}$ \\
\hline Rouault, veD ${ }^{b}$ & 2.10 & 0.15 & $2.04 \pm 0.06$ & $2.19 \pm 0.02$ \\
\hline Schomaker and Sargent, VED $^{c}$ & 2.066 & 0.09 & 2.03 & 2.12 \\
\hline Romanov and Spiridonov, SMED & 2.06 & 0.12 & $2.02 \pm 0.01$ & $2.14 \pm 0.01$ \\
\hline Present work, SMED & $2.061 \pm 0.002$ & $0.104 \pm 0.01$ & $2.020 \pm 0.007$ & $2.124 \pm 0.009$ \\
\hline
\end{tabular}

$\Delta(\mathrm{P}-\mathrm{Cl})=\left(\mathrm{P}-\mathrm{Cl}_{\mathrm{ax}}\right)-\left(\mathrm{P}-\mathrm{Cl} \mathrm{leq}_{\mathrm{G}}\right)$.

- Visual method of electron diffraction, ref. 3.

- Visual method of electron diffraction, ref. 4.

d Sector microphotometer method of electron diffraction. Parameters are $r_{\mathrm{a}}$ values, ref. 5.

- Sector microphotometer method of electron diffraction. Parameters are $r_{\mathbf{z}}(0)$ values, this work.

TABLE 4

MATRIX OF CORRELATION COEFFICIENTS ${ }^{\text {a }}$ FOR $\mathrm{PCl}_{s}$

\begin{tabular}{llllllll}
\hline & $r(P-C l)$ & $A r^{\mathrm{b}}$ & $l(P-C)^{\mathrm{c}}$ & $l_{\text {ax, eq }}$ & $I_{\text {eq,eq }}$ & $l_{\text {ax, ax }}$ & $R$ \\
\hline$r(\mathrm{P}-\mathrm{Cl})$ & 1.0 & 0.12 & -0.02 & 0.03 & -0.10 & 0.01 & 0.06 \\
$\Delta r$ & & 1.0 & -0.40 & 0.05 & -0.04 & 0.03 & 0.15 \\
$l(\mathrm{P}-\mathrm{Cl})$ & & & 1.0 & 0.26 & 0.03 & 0.04 & 0.46 \\
$l_{\text {ax, eq }}$ & & & & 1.0 & -0.04 & 0.06 & 0.55 \\
$l_{\text {eq,eq }}$ & & & & & 1.0 & -0.02 & 0.01 \\
$l_{\text {ax,ax }}$ & & & & & & 1.0 & 0.10 \\
$R$ & & & & & & & 1.0 \\
\hline
\end{tabular}

a Based on 136 intensity values interpolated from 331 experimentally observed data points. Matrix elements are given by

$$
\rho_{I J}=B_{I J}^{-1} /\left(B_{i t^{-1}} B_{J J^{-1}}\right)^{\frac{1}{2}}
$$

where the notation corresponds to that of O. Bastiansen, L. Hedberg ANd K. Hedberg, J. Chem. Phys., 27 (1957) 1311.

$\Delta r=r\left(P-\mathrm{Cl}_{\mathrm{ax}}\right)-r\left(\mathrm{P}-\mathrm{Cl}_{\mathrm{eq}}\right)$.

c. $l\left(\mathrm{P}-\mathrm{Cl}_{\mathrm{zx}}\right)-l\left(\mathrm{P}-\mathrm{Cl}_{\mathrm{eq}}\right)$ was constrained to be $0.008 \AA$.

\section{DISCUSSION}

The observed mean bond length, $2.061 \pm 0.002 \AA$, is in excellent agreement with that found recently by Romanov and Spiridonov ${ }^{5}$. This mean bond length is $0.019 \AA$ longer than that found ${ }^{33}$ in $\mathbf{P C l}_{3}$, in contrast to the situation in the analogous fluoride compounds, where the mean bond length in $\mathrm{PF}_{5}{ }^{1}$ is $0.019 \AA$ shorter than that found ${ }^{34}$ in $\mathbf{P F}_{3}$. The mean bond length is $0.068 \AA$ longer than that ${ }^{35}$ in $\mathrm{POCl}_{3}$.

The difference between axial and equatorial bond lengths, $0.104 \pm 0.01 \AA$, is found to be in reasonable agreement with the results of Schomaker and Sargent ${ }^{4}$ 
and Romanov and Spiridonov ${ }^{5}$, being nearly the average of these two results. This difference is approximately twice the difference found in PF $_{5}, 0.043 \pm 0.008$ $\AA^{1}$, and $\mathrm{AsF}_{5}, 0.055 \pm 0.010 \AA^{2}$. Gillespie's vSEPR model ${ }^{7,8}$ attributes this increase on going from the fluoride to the chloride to the greater repulsions between the bonding electron pairs in $\mathbf{P C l}_{5}$ stemming from the lower electronegativity of chlorine.

Mean amplitudes of vibration for $\mathbf{P C l}_{5}$ are of interest since insufficient information is available from the vibrational spectrum to make an unambiguous assignment for this and related molecules. Some spectroscopists ${ }^{36}$ have assigned the lower of the two $e^{\prime}$ frequencies to the in-plane equatorial bend, while others have conjectured that the alternative assignment is plausible on the basis of physical arguments $^{37}$ recently shown to be unreliable ${ }^{38}$. The experimental mean amplitudes differ from the calculated values by little more than expected from the uncertainties. They leave no doubt that the vibrational assignment in which the in-plane equatorial bending frequency is lower than the axial bending is superior to the alternative assignment. Analogous assignments in the cases of $\mathrm{PF}_{5}{ }^{1}, \mathrm{VF}_{5}{ }^{39}, \mathrm{AsF}_{5}{ }^{2}$, and $\mathrm{CH}_{3} \mathrm{PF}_{4}{ }^{38,40}$ also are called for by the electron diffraction studies of the compounds.

In all cases the results can be understood in an appealingly simple way, adopting the valence shell electron pair model ${ }^{7,8,38}$. The same resolution of pairrepulsions that accounts for the fact that axial bonds are longer than equatorial bonds - by virtue of greater axial-equatorial forces than equatorial-equatorial forces - also accounts for the greater restoring force for axial bending displacements than for equatorial in-plane bending displacements.

\section{NOTE ADDED IN PROOF}

The source of hydrolysis has been discovered to be a very small leak in the wall of the steam-heated line between the nozzle and sample vessel.

\section{ACKNOWLEDGEMENT}

It is a pleasure to acknowledge a generous allowance of computing time from the Michigan Computing Center.

\section{REFERENCES}

1 K. W. Hansen and L. S. Bartell, Inorg. Chem., 4 (1965) 1775.

2 F. B. Clippard, JR. AND L. S. Bartell, Inorg. Chem., 9 (1970) 805.

3 M. Rouault, Ann. Phys. (Paris), 14 (1940) 78.

4 Unpublished determination by V. Schomaker and H. Sargent, quoted in D. P. Stevenson AND D. M. Yost, J. Chem. Phys, 9 (1941) 403. 
5 G. V. Romanov and V. P. Spiridonov, Zh. Strukt. Khim., 8 (1967) 131.

6 L. S. Sutron, Tables of Interatomic Distances and Configuration in Molecules and Ions, Special Bulletin No. 11, The Chemical Society, London, 1958; ibid., No. 18, 1965.

7 R. J. Gillespie AND R. S. NyHolm, Quart. Rev. (London), 11 (1957) 339.

8 R. J. Gillespie, J. Chem. Educ., 40 (1963) 295; J. Am. Chem. Soc., 85 (1963) 4672; Inorg. Chem., 5 (1966) 1634; J. Chem. Educ., 47 (1970) 18.

9 A. Smith and R. H. Lombard, J. Am. Chem. Soc., 37 (1915) 2055.

10 T. Kennedy, D. S. Payne, R. I. Reed and W. Snedden, Proc. Chem. Soc., (1959) 133.

11 L. S. Bartell, K. Kuchitsu and R. J. De Neur, J. Chem. Phys., 35 (1961) 1211.

12 L. S. Bartell, in A. Weissberger AND B. W. Rossiter (Editors), Physical Methods in Chemistry, 4th Ed., Interscience, New York, in press.

13 L. S. Bartell and H. K. Higaingotham, J. Chem. Phys., 42 (1965) 851.

14 R. A. Bonham and L. S. Bartell, J. Chem. Phys., 31 (1959) 703.

is T. S. Sikand and R. A. Bunham, J. Chem. Phys., 48 (1964) 1688.

16 W. Heisenderg, Physik. Z., 32 (1931) 737; L. Bewilogua, Physik. Z., 32 (1931) 740.

17 L. S. Bartell, L. O. Brockway and R. H. Schwendeman, J. Chem. Phys., 23 (1955) 1854.

18 R. M. Gavin, JR. AND L. S. Bartell, J. Chem. Phys., 48 (1968) 2460.

19 V. SCHOMAKER AND R. G. GlaUder, Nature, 170 (1952) 290; R. G. Glauber AND V. SCHOMaker, Phys. Rev., 89 (1953) 667; J. A. Igers and J. A. Hoerni, Acta Cryst., 7 (1954) 405.

20 L. S. Bartell, J. Chem. Phys., 23 (1955) 1219; K. Kuchitsu and L. S. Bartell, $J$. Chem. Phys., 35 (1961) 1945.

21 L. S. Bartell and L. O. Brockway, J. Chem. Phys., 32 (1960) 512.

22 H. L. Cox, JR. AND R. A. Bonham, J. Chem. Phys., 47 (1967) 2599.

23 C. Tavard, D. Nicolas and M. Rouault, J. Chim. Phys., 64 (1967) 540.

24 D. R. Herschbach and V. W. Laurie, J. Chem. Phys., 35 (1961) 458; E. R. Liprincott and R. SCHroeder, J. Chem. Phys., 23 (1955) 1131.

25 L. O. Brockway and J. Y. Beach, J. Am. Chem. Soc., 60 (1938) 1836; Q. Williams, J. SheriDAN AND W. GoRdy, J. Chem. Phys., 20 (1952) 164; G. R. BAdGley AND R. L. Livingston, J. Am. Chem. Soc., 76 (1954) 261.

26 L. V. Vilkov, L. S. Khaikin, A. F. Vasilev and T. F. Tuliakov, Zh. Strukt. Khim., 9 (1968) 1071 .

27 R. A. Bonham and J. L. Peacher, J. Chem. Phys., 38 (1963) 2319.

28 L. S. Bartell, D. A. Koml, B. L. Carroll and R. M. Gavin, Jr., J. Chem. Phys., 42 (1965) 3079; T. L. BoATES AND L. S. BARTELL, to be published.

29 O. Bastiansen and M. Traetteberg, Acta Cryst., 13 (1960) 1108; Y. Morino, Acta Cryst., 13 (1960) 1107; Y. Morino, S. J. Cyvin, K. KuChItsu And T. IIJima, J. Chem. Phys., 36 (1962) 1109.

30 J. Brunvole, Acta Chem. Scand., 21 (1967) 473.

31 L. S. Bartell and B. L. Carroll, J. Chem. Phys., 42 (1965) 1135.

32 R. M. BAdger, J. Chem. Phys., 2 (1934) 128.

33 K. Hedberg aNd M. IWASAKI, J. Chem. Phys., 36 (1962) 589.

34 Y. Morino, K. Kuchitsu AND T. Moritani, Inorg. Chem., 8 (1969) 867.

35 T. MORitani, K. Kuchitsu ANd Y. Morino, to be published.

36 P. C. Van Der Voorn, K. F. Purcell. and R. S. Drago, J. Chem. Phys., 43 (1965) 3456; also see earlier work cited therein.

37 R. R. Holmes and R. M. Dieters, J. Chem. Phys., 51 (1969) 4043; R. R. Holmes, R. M. Dieters and J. A. Golen, Inorg. Chem., 8 (1969) 2612.

38 L. S. BARTell, Inorg. Chem., 9 (1970) 1594.

39 H. B. THOMPSON AND L. S. BARTELL, unpublished data.

40 L. S. Bartell AND K. W. Hansen, Inorg. Chem., 4 (1965) 1777.

J. Mol. Structure, 8 (1971) 23-30 